\title{
SPOTLIGHT ON CAREERS
}

\section{Interview with Dr. Claudia Hui - an Analyst at Bloom Burton \& Co.}

\author{
By Rebecca Liu
}

"Dr. Claudia Hui completed her PhD in Immunology at McMaster University investigating how genetic and environmental factors influence the development of allergic diseases and asthma, with particular emphasis on the role of epithelial-derived mediators in linking epithelial injury, tissue responses, and the recruitment and differentiation of progenitors into effector cells of allergic disease. Prior to this, Dr. Hui received her MSc in Physiology and Pharmacology from McMaster University and a BSc. in Physiology from McGill University. Dr. Hui is currently working as an Analyst at Bloom Burton \& Co., a healthcare-specialized investment bank in Toronto, where she conducts technical and commercial due diligence and strategy consulting in biotechnology and healthcare. Dr. Hui's expertise helps the Bloom Burton \& Co. team with monetization planning and determining the fundamental value of companies across all healthcare sectors."

1) What steps did you take to find or acquire this position? In particular, what educational background and extracurricular involvement helped prepare you for this position?

I stumbled across this position serendipitously, but I would say discipline, hard work and sheer tenacity landed me this job. I had initially considered going into Management Consulting (in September 2013). To prepare myself for a change in career path from academia to that, I did a lot of research and spoke with several Management Consultants.

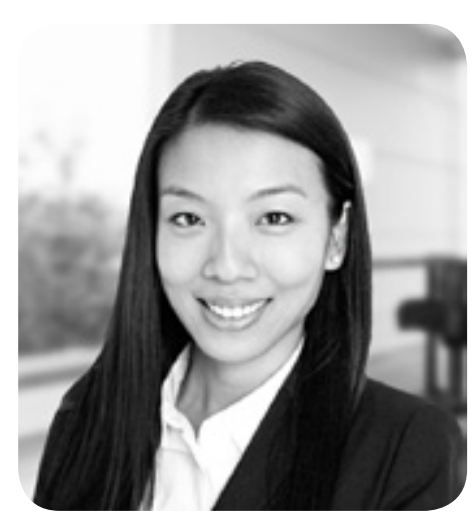

I joined McMaster's Graduate Management Consulting Association (GMCA) and signed up for the various courses they offered, including Mini MBA Lecture Series and Practice Case Interview Series.

In April 2014, Bloom Burton \& Co. advertised their exclusive networking event for those interested in employment opportunities through GMCA. I submitted my resume and was selected to attend. During the event, I met everyone at the firm and gained valuable insight on Bloom Burton \& Co., the people and culture, and its values.

Following the event, I reached out expressing my interest for a job as a contract consultant; however, nothing panned out (immediately) - I was told that I would be contacted when the Bloom Burton \& Co. team has the need for my assistance. I was disappointed and a little deflated. However, in May 2014, the opportunity presented itself: Bloom Burton \& Co. contacted me for an opportunity to work on an ad-hoc project as a contract consultant. Although I was wrapping up my experiments, writing up my thesis and preparing for my defense, I knew this was an opportunity I had to take. One project led to another, and before I knew it, I contracted on various projects while finishing my PhD.

In September 2014, Bloom Burton \& Co. was hiring for an Analyst. Given that my previous experience had all been limited to jobs in research and academia, I reached out 
to a few of my contacts to gain insight on what industry would be looking for. I was invited to do a case study, and subsequently, an in-person interview. Again, I turned to my contacts to familiarize myself with industry interviewing processes. I even did three to four mock interviews with them. I was offered the position in late November 2014! And officially made my jump into industry and started my career as an Analyst in January 2015.

\section{2) What unique non-academic skills do you believe are most valuable in your current position?}

Curiosity and skepticism. It is important to be curious, and also to have the desire to learn more and seek evidence to support the information and data companies present to you. I think in science especially, people always try to showcase their best results, and so it is important to be critical of data and conclusions companies present to you and not blindly believe everything they tell you.

\section{3) Can you briefly describe one of the projects you are currently working on?}

One of my current projects involves advisory and support work that covers a broad range of tasks, mainly indication, product and company assessments, and prioritizing new opportunities that align with our client's business model. I explain each of these briefly below:

Indication Assessment: Involves providing the client a general overview of the specific indication of interest, standard of care, unmet need, clinical path, market dynamics (i.e., market size, pricing, reimbursements, etc.) and competitive landscape. Our deliverable informs the client whether the indication of interest provides a sound business case.

Product/Company Assessment: Includes both the assessment of companies, as well as individual assets (a program within a company that our client may be interested in acquiring or in-licensing). Our work covers early-stage all the way to commercial-stage companies. This also includes review of data room material (i.e., experimental data, intellectual property, regulatory filings and correspondences, balance sheets, etc.). Our deliverable includes an assessment on the merit of the science, indication, market potential, timelines and inflection points, competitive landscape, etc. We also suggest potential deal structures and possible next steps our client could take.

Company Triaging: Over the span of several months, we assessed numerous companies and products and provided an individual assessment on each opportunity. Our interim deliverable included a product/company review matrix that prioritized the opportunities based on a list of criteria we assessed, and this in turn allowed our client to pursue specific opportunities and to start the negotiation process.

\section{4) What are some of the benefits and drawbacks of your current position and how does it relate to your training in allergy and autoimmunity (if applicable)?}

My firm is quite unique in the sense that it is an investment bank, but we also have other services we provide, such as consulting and company incubation.

With that said, there are many benefits of my current position. First and foremost, I get to wear many different hats depending on whom our clients are. I get to interact with senior management, as well as leading scientists who discovered the technologies.

Furthermore, I love learning and this job allows me to learn on the job, every day! I learn about different technologies and indications, which allows me to develop detailed knowledge about the various technologies and sectors. I learn to analyze companies and science from the perspective of investors, which is something that does not come naturally to a scientist. I also get to put my education to use. My PhD comes in handy since immunology tends to play a big role in drug development.

Finally, as a scientist by trade, we all hope to see (our) research go from bench side to bedside. My current position gives me the opportunity to do exactly that - I get to partake and witness great science and technologies go from the labs to the clinics.

A drawback is that the field moves very quickly. While that can be very exciting, it also means that I constantly have to keep up with the latest advances in the field, all of which can and will have a direct impact on my work, whether assessing new technologies and companies, or providing advisory work for companies. However, this is no different than when I was in graduate school, where I constantly had to keep up with the latest publications and discoveries in my field. What is different now is that I no longer just follow the allergy and immunology space, but I have to follow the full spectrum, from oncology to schizophrenia, to rare orphan diseases. Consequently, the hours can get pretty long and I find myself sitting in front of the computer a lot.

5) Can you give any advice to graduate students looking to pursue a career within your field? 


\section{Health Science InQuiry}

$\sim$ I will pass on an advice that I received from a professor and mentor of mine before I started my job at Bloom Burton \& Co:"Always be skeptical of the science/data. Most of what you will see will be cherry-picked and "spun". Never take anything at face value."

Through my own experience, another piece of advice would be to NETWORK! People and companies are always looking for talent, and many times, it is just a matter of meeting the right people at the right time.

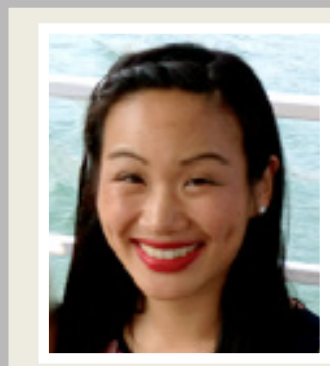

Rebecca Liu

Rebecca H. Liu is a second-year PhD candidate in Health \& Rehabilitation Sciences (Health Promotion) at the University of Western Ontario. Her research focuses on using health coaching as a behavioural intervention among specialized populations to reduce cardiometabolic health risk. 